\title{
Problem Based Curricula and Problem BASED LEARNING IN PHYSIOTHERAPY: A CRITICAL REVIEW
}

\begin{abstract}
Introduction: Problem based curricula and problem based learning are used extensively to facilitate learners to become effective learners and through that, effective professional problem solvers. The basic characteristics of the problem based curriculum and the processes of the problem based learning are described in the literature but many variations of problem based learning and the problem based curriculum exist. Research findings are also contradictory regarding the effectiveness of these approaches. The aim of this article is to discuss the theoretical foundation of these approaches and to identify the core issues that must be addressed in order to optimize their effect on learners.
\end{abstract}

EKSTEEN C A

B.Sc Physio; MEd, PhD'; $J$ A SLABBERT

B.Sc Hons; MEd, PhD²

\footnotetext{
'Department of Physiotherapy,

University of the Pretoria.

2 Associate Professor, Faculty of Education, University of the Pretoria.
}

Methodology: A literature search was done by using the following keywords: problem based curriculum, problem based learning, clinical decision making, clinical problem solving, clinical judgement, physiotherapy, medicine, health care, and health care education.

Discussion: There is a lack of research in the literature that shows evidence that the problem based curricula and problem based learning is more beneficial for students'learning or mastering specific competencies than learning in a traditional curriculum. Papers on problem based curriculum and problem based learning describe the process and state the desired effects of the teaching approaches without explicitly describing the contextual and transactional environments, as well as the internal (departmental) environment in which the change in teaching approach took place and how it was adapted to their situation. Furthermore, no research could be found on ways to address the negative outcomes of problem based learning. There is thus a need for well designed research protocols to show the best evidence of physiotherapy educational practice.

\section{KEY WORDS: PROBLEM BASED CURRICULA, CLINICAL DECISION MAKING, CLINICAL JUDGEMENT, HEALTH CARE EDUCATION.}

\section{INTRODUCTION}

Problem based curricula and problem based learning have been developed as teaching approaches as a result of lecturers striving to solve the problems that learners in the health care field experience in clinical problem solving when confronted with patient care (Boshuizen and Schmidt, 1995). Physiotherapy teachers are included in this group. Incompetence in clinical problem solving is a result of learners' constrained perceptions of the relationship between knowledge gained during formal teaching in physiotherapy and the essence of patient care.

Learners experience the acquisition of knowledge in 'classrooms' as a prerequisite for the application of knowledge in clinical practice. This implies that they have to memorise facts and concepts in order to apply them in clinical practice. It also implies the memorisation of skills and techniques, to be able to repeat and apply them in clinical practice. When learners are confronted with clinical practice they assume that the knowledge they have acquired is sufficient to make them successful practitioners. This leads to the misconception that knowledge of facts, concepts, skills and techniques is the essence of physiotherapy practice.

The continuous knowledge explosion experienced by all health care professions leads to stifling the already content-crammed curricula. The emphasis on content-based curricula is reflected in the assessment practice of health care education (Towle, 1991). This emphasis on content in the assessment of learners promotes memorisation of knowledge. This is observed by the researcher even in the so-called problem based curricula. Memorisation is the lowest form of learning and takes place when content is carefully packaged and/or structured by the educator and offered to the learner, who then passively absorbs and stores it in his/her memory. The consequence is that the learner can only reproduce what has been stored, without the competence of being able to at least utilise it properly in relevant situations with which he/she is confronted. Assessment practice in physiotherapy education therefore has a

CORRESPONDENCE TO:

C A Eksteen

(BSc Physio; MEd, PhD)

Senior Lecturer

Department of Physiotherapy

University of Pretoria

P.O. Box 667

Pretoria 0001

Tel: (012) 354-1249

Fax: (012) 354-1226

E-mail: ceksteen@medic.up.ac.za 
major influence over learner competence in clinical problem solving. To take initiative for learning means to collect, analyse, organise, and critically evaluate content or knowledge with the primary purpose to utilise the knowledge in practice.

The discussion in the former paragraphs implies that the expected outcomes in physiotherapy education must be closely scrutinised to ensure that the misconceptions of physiotherapy practice do not originate in the education thereof, in spite of the best of intentions. The focal point in physiotherapy education should rather be the construction of new meaning (deep learning) through problem solving, to help learners to not only meet, but also to exceed the demanding challenges of the future in physiotherapy practice.

Physiotherapy practice always constitutes a problem to be solved as a point of departure. Learning physiotherapy can therefore not be seen out of the context of problem solving. Researchers found that learners who learn through solving problems are actually constructing knowledge or meaning, and that these learners:

have a better long-term memory of that knowledge;

- are capable of recalling the knowledge with more ease than learners who master the knowledge through transference and memorisation; and can utilise the knowledge appropriately to solve subsequent problems (Solomon, 1994).

The manner in which learners learn and the basis on which the learning is founded therefore has an influence on learners' ability to solve problems in practice. This ought to be a fundamental consideration in physiotherapy education.

According to Jones, Jensen and Rothstein (1995), knowledge as such cannot be sufficient in solving a problem in practice, because physiotherapists should, in addition to knowledge, be able to carefully consider all factors pertaining to the problem of a patient before making a decision on the way in which to solve it most effectively. The authors (Ibid) describe the latter type of decision-making as 'wise action'. This wise action is of fundamental importance, because it implies an activity or process (action) of uniqueness and ingenuity (a 'wise action'). This refers to the learning process of problem solving, where the learner constructs meaning when a challenging problem is solved. Learning can therefore be described as the construction of meaning by the learner (Slabbert, 1996). Meaning (knowledge) has to be constructed (generated through 'wise action'). These two very distinctive aspects are therefore distinguished in problem solving, namely a process of 'wise action' (construction of meaning) and the content (knowledge) that has been constructed.

Many variations of the problem based learning approach are found in the literature due to the fact that educators adapt the problem based learning approach to their specific staff and environmental circumstances. This makes a comparison between a problem based learning approach and a conventional curriculum very difficult (Hayes, 1998). It probably also explains the difference in research outcomes why some PBL approaches achieve better results than the conventional teaching approach and others show no difference between the two approaches.

A problem emerges from the previous discussion namely a lack of understanding of what the fundamental contribution of the problem based curriculum and problem based learning are before addressing the discussed problems in physiotherapy education. If the suggested approaches do not influence the way learners think and act there will be no difference found between the problem based learning approach and the conventional teaching approach. The question then is: what are the core aspect(s) of a problem based curriculum and/or problem based learning that need to be addressed in order to enhance learners' clinical problem solving abilities?

The aim of this article is to discuss the theoretical foundation of a problem based curriculum and problem based learning as teaching approaches, to give a better understanding of the ways in which learner potential can be optimised. This article does not aim to give the advantages and disadvantages of each approach, but rather discusses how they compliment each other and what the foundational shortcomings are.

\section{METHODOLOGY}

The methodology followed in this article is an analysis of practice, based on a literature review. The keywords used in the literature search were problem based curriculum, problem based learning, clinical decision making, clinical problem solving, clinical judgement, physiotherapy, medicine, health care, and health care education. The data bases used for the literature search were Current Contents: Clinical Medicine, Cinahl, MEDLINE, PUBMED, ERICCurrent Index to Journals in Education (CIJE), Exerpta Medica, and Social Sciences Citation Index. The reference lists of relevant articles were also hand searched for relevant literature not found through the electronic databases. The core aspects in the literature pertaining to the aspects covered by the key words were identified, analysed, synthesized and described to formulate a foundation for curriculum development and teaching approach (which includes assessment of learners) for physiotherapy education.

\section{Problem-Based Curriculum}

Barr (1977) describes a problem-solving curriculum design for physiotherapy. In this curriculum design content is organised around similar problems around a specific theme. The objectives (learning outcomes) are formulated and the content from basic medical sciences (social and medical sciences) needed to solve the problems, is categorised under the different basic subjects (for example anatomy, physiology, pathology) from which knowledge is borrowed to solve the problem. The author (Barr 1977) does not describe a change in the teaching approach together with the change in the compilation and organisation of the curriculum, although she describes criteria on how the learners should go about writing down the answer to the problem or solving the problem.

A term that is used alternatively with the problem based curriculum is the integrated curriculum. 'An integrated PBL curriculum focuses all learning of 
content, including basic science, around health care scenarios' (Saarinen-Rahika and Binkley, 1998).

The rationale behind the re-organisation of the curriculum, in the form of statements and problems, is to enable learners to integrate knowledge in order to solve problems. Learners should therefore learn to: “...see relationships between the different elements and process a variety of concepts and data. The more complex the problem the more data must be analysed and synthesized and the greater the variety of the sources of the data (May, 1977)".

According to Barr (1977) a problem based curriculum enhances:

- lifelong learning;

- the sharing of knowledge with fellow learners and colleagues of other disciplines;

- active involvement of the learner through his/her education (learning).

However, a potential problem in a problem based curriculum is that the content of different subjects from which learners must obtain knowledge in order to solve a problem is already integrated by the curriculum specialists. The learners are therefore presented with, told or guided 'which knowledge to use', to solve the problem. They are thus denied the opportunity to identify the relationships between facts, concepts, laws and theories themselves. In the latter case, the learners therefore do not need to construct meaning (do deep learning), because the knowledge has already been constructed for them. At the other end, Saarinen-Rahika and Binkley (1998) reports that in completely integrated programs, students experience relatively high levels of stress which could be attributed to the unfamiliar learning method, as well as the volume of content to be learned.

In the problem based curriculum as a way in which learning is enhanced the lecturer has a dichotomous problem. On the one hand s/he must facilitate learning in the learners, based on the principle that they must be able to start asking questions, gathering information/ knowledge and create a solution to a problem which is the best solution for that particular problem at that particular time. On the other hand it is very difficult for students to gather relevant information/ knowledge from different fields of study i.e. physics, chemistry, or any of the relevant social sciences, without some form of structure such as a curriculum in which the content is organised in a pre-selected sequence.

According to Barrows and Tamblyn (1980), Solomon (1994) and Kruseman (1996) a problem based curriculum design goes hand in hand with a change in teaching approach. The learners are presented with a statement or a problem which they must discuss or solve. (This problem is the stimulus which facilitates learning). Through discussion of statements and the process of finding a solution and/or solutions to the problems learners master the relevant subject content. Because content from different subjects is needed to solve a problem, the statements or problems that the learners must discuss or alternatively solve are formulated around selected themes based on knowledge from different subjects such as anatomy, physiology, pathology and others.

In an applied science such as physiotherapy, relevant knowledge from, for example, anatomy, physiology, pathology, physics, chemistry, etcetera, is used to solve problems in physiotherapy. Obtaining knowledge compels learners to acquire the relevant knowledge (e.g. physiology, anatomy, pathology, physics, chemistry) and to use it in solving the problem effectively. The fact that learners who are educated through a problem based curriculum do not fare as well in terms of basic knowledge about basic subjects as their counterparts in traditional education can be attributed to the fact that in the traditional teaching of anatomy for instance, learners learn anatomy for the sake of anatomy and not anatomy as it is relevant to physiotherapy. In a problem based approach, learners learn anatomy as relevant to physiotherapy. Their knowledge base of anatomy per sé will therefore be of a different emphasis (Solomon 1994). However, Coulson and Osborn (1983) found that after 12 weeks, and Eisenstadt et al (1990) found that after two years, there is no longer a difference in knowledge base of learners educated in the two approaches. The results of studies comparing learners in a PBL curriculum program and learners in a traditional curriculum with respect to outcomes are difficult to interpret, due to potential confounding factors and a lack of valid measures of clinical and professional performance (Saarinen-Rahiika and Binkley, 1998). What is however clear from this debate is that the difference in basic knowledge base is one of quality of knowledge versus quantity of knowledge. The former is of much more importance in physiotherapy practice. It is obvious that although the problem based curriculum focuses on relevant knowledge (quality) needed in the different subjects in order to solve the problem, successful integration between quality and quantity of knowledge to enhance the quality of the outcomes is still problematic.

Of more importance is that problems (statements) formulated in the problem based curriculum should be formulated on the basis of and in accordance with the body of knowledge of physiotherapy as well as the methodology of the discipline. Since it is the structure displayed by the body of knowledge as well as the methodology of a discipline that makes it understandable, learnable and usable (Schwab 1964), problems formulated without considering this will cause difficulty in discovering the relevant relationship between facts, concepts, principles and laws on which reasoning in the subject discipline (physiotherapy) is founded. If the problems formulated to facilitate learning of physiotherapy are not based on the body of knowledge of physiotherapy as well as the methodology of the discipline, the problems mentioned before will be perpetuated. In such a case the necessary competencies that learners should obtain is not based on a comprehensive, integrated, holistic conceptualisation of physiotherapy practice which is required of professionals. This conceptualisation is found in the structure of a discipline which consists of two very significant and distinctive parts. According to Schwab (1964), a discipline's structure consists of a body of knowledge (constructed meaning/ known facts, principles, processes and relationship between them) as well as 
the way in which this body of knowledge came into being (the way in which meaning is constructed also called the methodology of the discipline). These structures are called the substantive and syntactical structure respectively. The substantive structure or body of knowledge (constructed meaning or known content), contains the content (facts, concepts, generalisations, principles, laws, theories and the integrated relationship between these) which may have a structural composition, or process (procedure, action, practice, routine, method) nature. Physiotherapy has an essential process nature as its substantive structure (body of knowledge) because it consists of the process of evaluating and treating a patient as its content. The 'structural' knowledge used in physiotherapy is not essentially physiotherapeutic, because it represents the relevant knowledge from other disciplines used in physiotherapy. The syntactical structure (the way in which meaning is constructed) contains the methodology of the discipline (the scientific method of investigation through which knowledge in the form of structural content or process content has been generated). In the case of physiotherapy, it is the scientific method of investigation (methodology) through which the process of evaluating and treating a patient (process content) is constructed. After the latter is constructed, it exists as process content and can be executed on a patient.

The problem based curriculum is obviously concerned with the substantive structure (content) of the discipline. In research on the problem based curriculum there is no evidence that the problems and the way in which they are formulated are based on the substantive structure of physiotherapy as a discipline. This may be one of the reasons why the problem based curriculum does not fulfil the expected outcomes in physiotherapy education.

\section{Problem Based Learning (PBL)}

With problem based learning, the emphasis moves from curriculum to learner. This relationship between the problem based curriculum and problem based learning is indicated by the following quotation from Solomon (1994):

"PBL is an educational process where learning is centred around problems as opposed to discrete subject-related courses."

Both Barrows (1980) and Schmidt (1983) describe problem based learning as an educational approach which was developed to overcome problems that were experienced by medical students in practice. Problem based learning would, according to the authors, enable learners to obtain an integrated subject knowledge (body of knowledge) related to the problem, as well as to develop and enhance problem solving competency.

The process of problem based learning as an educational approach can be divided into four steps, namely:

i) challenging the learners (divided into small groups) with a problem or statement;

ii) small group discussion by the learners;

iii) self-study by the learners of the content that they have to master; and

iv) exchange of information among learners in the small group.

The learners are challenged with a statement or problem which they have to reason, explain or solve. The statement or problem is formulated in such a way that it directs the learners' learning.

Schmidt (1983), Kruseman (1996) and Barrows and Tamblyn (1980) all describe seven steps by which learners work in small groups to solve the problem or debate the statement. A summary of the process that the learners must go through in small groups, is mentioned briefly:

i) the explanation of terminology and concepts that they do not understand;

ii) defining the problem (during this step the learners should make a list of the phenomena which need to be explained);

iii) analysis of the problem in that the learners define as many different explanations for the phenomena as possible by using previous knowledge and common sense;

iv) the drawing-up of a systematic representation of the explanations that are deduced from step 3 in order to describe the information through which the phenomena are explained in a comprehensive process;

v) formulation of learning objectives;

vi) the collection and assimilation of information during a self-study period outside the group; and

vii)the sharing and integration (syntaxis and testing) of the newly gained knowledge.

The purpose of the preceding steps is to help the learners become self-directed. Schmidt (1983) describes three factors which facilitate learning through the preceding process of problem based learning, namely:

- during the process through which knowledge is obtained the pre-knowledge which the learners already have is activated (actualised). According to Schmidt (1983) learning is a restructuring process which enables the learner to process new knowledge about a particular topic on the basis of his/her pre-knowledge, in an easier way;

- the greater the similarity between the situation that is sketched in the 'problem' and reality, the better the learner's success would be in the execution of the learning action. This is known as coding-specificity; and

- new knowledge is better understood, processed and recalled if learners have the opportunity to elaborate on the knowledge they have mastered, or to explain to fellow group members what they have learned. Learners are given the opportunity during the implementation of problem based learning to explain to their peer group what they have learned, to educate the group there-in, to answer questions about it and/or to discuss a particular topic, to write summaries about it and to formulate hypotheses about a given problem and/or to evaluate it critically.

According to Solomon (1994) learning is also facilitated by:

- providing a context in which knowledge can be recalled; and

- stimulating learners to expand their knowledge. 
Barrows and Tamblyn (1980) emphasise furthermore that an atmosphere which enhances learning in the groups should be established and that co-operation, mutual support of one another, joint responsibility for group functioning and also critical evaluation of fellow group members should characterise the functioning of the groups in order to optimise learning.

The facilitation of the learners' reasoning process during the solution of the problem is dealt with by a facilitator (educator or tutor). The educator (or tutor) may encourage learners during the execution of the learning action, or may interrupt the process to focus their attention on a particular aspect, or to re-direct the discussion. The way in which facilitating learning is described in problem based learning makes it clear that the educator or tutor controls the process. Facilitating the learners through the framework of a challenging problem so that the learners remain in a continuous relationship with the learning task is not the primary aim.

According to Barrows (1983) and Solomon (1994) problem-based learning, as an educational method within the problem oriented or problem based curriculum, has as a result that learners:

i) are more knowledgeable in the solving of problems;

ii) become lifelong learners;

iii) develop good interpersonal skills;

iv) develop application (and integration) of cognitive, communication and manipulative competencies in practice;

v) have better long term memory of the acquired knowledge;

vi) are more motivated to learn and also prefer the problem based learning approach to the traditional way of educating; and

vii)use more hypothesis-deductive reasoning in the solution of problems than learners who are educated in traditional ways and who reason deductively.

However, Patel et al (1991) found empirically that learners who were educated by means of problem based learning in their particular environment and system make substantially more mistakes in the explanation of clinical diagnostic findings than learners who are educated in a traditional curriculum. The reason for this probably lies in the fact that problem based learning enhances backward-reasoning (hypothetico-deductive reasoning) to the detriment of the mastering of forward-reasoning (inductive reasoning) and formation of sophisticated knowledge which is necessary for making a diagnosis and which is characteristic of expert clinicians. There is also concern that the achievement of learners (short-term recall of facts) who followed the problem based learning approach is often lower than that of learners who were educated in the traditional approach, where the emphasis is on basic knowledge. Long term retention of facts is better in learners who are educated through a problem based approach. On the other hand, some researchers indicated that the difference in ultimate achievement between learners who are educated in the traditional way and those who are educated through the problem based learning approach is not very significant (Norman and Schmidt 1992; Kruseman 1996).

The fact of the matter is that problem based learning does not fulfil the expected outcomes of physiotherapy education in relation to the demands of the future. Reflection on problem based learning, as described in this paragraph, indicates that the essence of problem based learning is situated in the learning process. A characteristic feature of this learning should be that learners are able to act 'wisely'. There can be no doubt that 'wise action' has to be initiated. This can only be done through a challenging problem which demands 'wise action' to be taken. However, the problem obviously needs to demand not just any 'wise action', but a particular 'wise action' which will result in the best solution to the problem. This refers to the learning process (construction of meaning) which has to have its particular competencies determined by the syntactical structure (methodology) of physiotherapy as a discipline. That which is revealed here is the fundamentally important relationship between problem based learning and the dichotomous structure of a discipline: the syntactical structure needs to be implemented to discover or construct the substantive structure (Schwab, 1964) - which is exactly the intention of problem based learning.

The outcome of problem based learning has the same shortcomings as that of the problem based curriculum. The shortcomings in problem based learning, however, are situated in the nature of the problem and the demanding criteria to which a problem formulated by the lecturer using the PBL approach should adhere to in order to compel learners to implement the particular learning process unique to physiotherapy as a discipline. This constitutes that the syntactical structure of physiotherapy, which has already been established, is not to be distinguished from the eclectic combination of many theories attempting to qualify physiotherapy as a unique discipline.

It is therefore the conceivable absence of a description of the syntactical structure of physiotherapy as a discipline which is the basic shortcoming giving rise to the unsatisfactory outcome of physiotherapy education, and which needs to be addressed.

\section{CONCLUSION}

The problem based curriculum and problem based learning go hand in hand. Whereas the problem based curriculum should be based on the substantive structure of physiotherapy as a discipline, problem based learning emphasises the initiation and the process of clinical problem solving. The latter is called the syntactical structure of the discipline. This approach claims to enhance a learner's ability to create a structure in which knowledge can be recalled and which serves as basis for the generation of new knowledge (research in physiotherapy). The process learners use to solve a problem is a similar process used to generate new knowledge in physiotherapy.

To learn effectively a learner should not only be able to be a versatile learner, but also be able to control his learning process (be a meta-learner) and to adapt his/her learning strategy to acquire the relevant cognitive, psychomotor and communicative competencies to complete the learning task (Slabbert 
1988). The outcomes of problem based learning that were mentioned serve as an indication of the result of problem based learning as a teaching approach on learners' personal competence to act professionally. Papers on problem based curriculum and problem based learning describe the process of how to solve a problem and the (desired) effects of the teaching approaches without explicitly describing how it was adapted to the contextual and transactional environments, as well as the internal (departmental) environment in which the teaching approach took place. It is therefore difficult to compare the results of problem based learning approaches which were applied in various centres. Furthermore, no reşearch could be found on ways to address the negative outcomes of problem based learning physiotherapy. There is thus a need for well designed research protocols to show the best evidence of problem based curriculum and problem based learning as educational approaches in physiotherapy.

\section{REFERENCES}

Barr J S 1977 A Problem-solving Curriculum Design. Physical Therapy 57(3): 262-264

Barrows H S 1980 Problem based learning: An Approach to Medical Education. New York
Barrows H S 1983 Problem-based, Selfdirected learning. Journal of the American Medical Association 250(22): 3077-3079

Barrows H S, Tamblyn R M 1980 Problembased learning: an approach to medical education. Volume 1. New York: Springer

Boshuizen H P A, Schmidt H G 1995 The development of clinical reasoning expertise. [n: Clinical Reasoning in the Health Professions. Oxford: Butterworth-Heineman.

Coulson R L, Osborne C E 1983 Problem based learning of the cardiovascular system using the problem-based learning module. Physiologist 26: 220-224

Eisenstadt R S, Barry W E, Glanz K 1990 Problem based learning: cognitive retention and cohort traits of randomly selected participants and decliners. Academic Medicine 65: s11-s 12

Hayes S H 1998: Invited commentary. Physical Therapy 78(2): 207-209

Jones M, Jensen G, Rothstein J 1995 Clinical reasoning in physiotherapy. In: Clinical reasoning in the health professions. Oxford, Butterworth-Heineman

Kruseman A N 1996 Workseminar on 'Problem based learning' 26-27 September. Pretoria: Faculty of Medicine.

May B J 1977: An integrated problem solving curriculum design for Physical Therapy education. Physical Therapy 57(7): $807-812$
May B J, Newman J 1980 Developing competence in problem-solving: a behavioural model. Physical Therapy 60: 1140 - 1145

Patel V L, Groen G J, Norman G R 1991 Effects of conventional and problem based medical curricula on problem solving Academic Medicine 66: 380 - 389

Saarinen-Rahiika H, Binkley J M 1998 Problem based learning in Physical Therapy: A Review of the literature and Overview of the McMAster University Experience. Physical Therapy 78(2): $195-211$

Schmidt H J 1983 Problem-based Learning: rationale and description. Medical Education 17: $11-16$

Schwab J J 1964 Structure of disciplines: meanings and significances. In: The structure of knowledge and the curriculum. GW Ford and L Pugno (editors). Chicago: Rand McNally: $6-30$

Slabbert J A 1988 Die ontwikkeling van 'n metaleermodel. DEd dissertation Pretoria: University of Pretoria

Slabbert J A 1996 A quantum leap to excellence - the challenge for education. (Manuscript for publication).

Solomon P 1994 Problem-based learning: a direction for physical therapy education? Physiotherapy Theory and Practice 10: 45-52

Towle A 1991 Critical thinking: the future of undergraduate medical education. London: King's Fund Centre. 